\title{
Stress analysis of mandibular two-implant overdenture with different attachment systems
}

\author{
Shin TAKESHITA, Manabu KANAZAWA and Shunsuke MINAKUCHI \\ Complete Denture Prosthodontics, Department of Masticatory Function Rehabilitation, Division of Oral Health Sciences, Graduate School of Medical \\ and Dental Sciences, Tokyo Medical and Dental University, 1-5-45 Yushima, Bunkyo-ku, Tokyo 113-8549, Japan \\ Corresponding author, Manabu KANAZAWA; E-mail: m.kanazawa.ore@tmd.ac.jp
}

\begin{abstract}
This study aimed to investigate the influence of different overdenture attachment systems on the stress generated in peri-implant bone during overdenture dislodgement and loading. Two implants were placed in the canine regions on an acrylic edentulous mandibular model. Four strain gauges were attached to the resin surface adjacent to the left implant. Bar, ball, and magnetic attachments were examined. Three experimental overdentures were fabricated, and the denture parts of the attachment systems were incorporated into the mucosal surface. Retentive forces and strains generated in peri-implant bone during three types of dislodgement (vertical, anterior and posterior) and loading (left first molar region, right first molar region and mid-anterior region) were measured. The bar attachment showed the highest retentive force and reduced strain on posterior dislodgement. The ball attachment demonstrated the largest strain on loading at molar regions. The magnetic attachment showed the smallest retentive force and little strain.
\end{abstract}

Keywords: Implant overdenture, Attachment systems, Strain gauge, Dislodgement, Loading

\section{INTRODUCTION}

The aged population continues to increase worldwide ${ }^{1,2}$. Even though there is a decline in total tooth loss in the United States, there will be a net increase in the number of edentulous people with the growing numbers of older people overall ${ }^{3)}$. Therefore, the needs for treatment of edentulous patients are also expected to grow. The restoration of the edentulous mandible with an overdenture supported or retained by two implants placed in the interforaminal region is regarded as the first prosthodontic treatment option ${ }^{4}$. A healing period of 3 to 6 months before functional loading of the implants has been recommended for proper osseointegration ${ }^{5}$. However, this healing period prior to prosthesis placement might be intolerable aesthetically, functionally, psychologically and socially for edentulous patients ${ }^{6)}$. Therefore, the period with no prosthesis is undesirable for edentulous patients, and immediate loading of mandibular two-implant overdenture is the most appropriate treatment option for edentulous patients.

Immediate loading of four splinted implants in the interforaminal region supporting mandibular overdentures retained by bar attachments was regarded as a predictable procedure because of the high survival rates, adequate number of subjects and long follow-up duration reported ${ }^{7}$. On the other hand, immediate loading of one or two implants supporting mandibular overdentures retained by bar attachments ${ }^{8)}$, ball attachments $^{9-11)}$, locator attachments ${ }^{12)}$ or magnetic attachments $^{13)}$ has been evaluated. However, the sample size was small, and the follow-up duration was only 1 year in those reports. Notably, Kronstrom et al. concluded that immediate loading of one or two implants supporting mandibular overdentures retained by ball attachments with O-rings should be performed with caution because the survival rate was $81.8 \%{ }^{10)}$. Therefore, the existing reports could not provide strong evidence for immediate loading of two implants supporting mandibular overdentures $^{8-13)}$

The load on implants immediately after surgery may be sufficient to cause micro-damage in the peri-implant bone, even though a load of the same magnitude may not cause failure after achieving osseointegration $^{14)}$. Therefore, the protocol of immediate loading of implants supporting overdentures restricted overdenture removal by the subjects themselves ${ }^{9-12)}$ or chewing hard food ${ }^{11,12)}$, in view of disturbing the process of osseointegration. Stress transferred to the implants or peri-implant bone under occlusal force to the implant overdentures has been well documented ${ }^{15-23)}$, while stress around the implants during overdenture dislodgement has not been investigated in detail. Consequently, in vitro measurements on an edentulous mandibular model simulating the intraoral environment and an experimental mandibular two-implant overdenture by means of strain gauges attached to the bone adjacent to the implant were performed in this study.

The purpose of this in vitro study was to investigate the influence of different attachment systems for implant overdentures, namely the bar attachment, the ball attachment and the magnetic attachment, on the retentive forces and stresses generated in the peri-implant bone during overdenture dislodgement and loading. The working hypothesis was that the type of attachment system influences the retentive forces and stress generated in the peri-implant bone during overdenture dislodgement and loading. 


\section{MATERIALS AND METHODS}

\section{Attachment systems}

The attachment systems examined in this study were as follows (Fig. 1).

1. Bar attachment: The bar attachment consisted of two gold abutments (Gold Abutment Bar Implant Level, Nobel Biocare, Göteborg, Sweden), a roundsection bar, $1.9 \mathrm{~mm}$ in diameter, and clip (CM

(a)
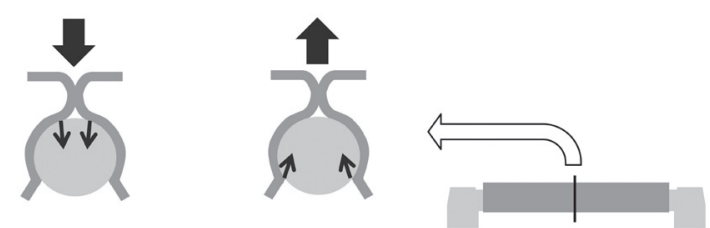

(b)
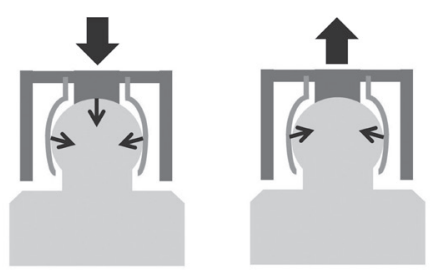

(c)

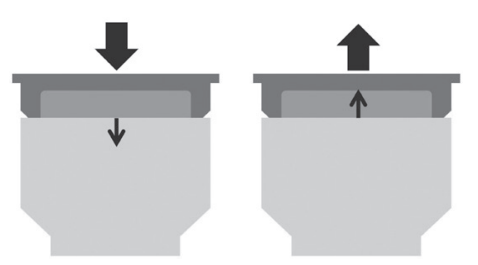

Fig. 1 Cross-sectional scheme of the attachment systems and the load transmission. (a) bar attachment, (b) ball attachment, (c) magnetic attachment.

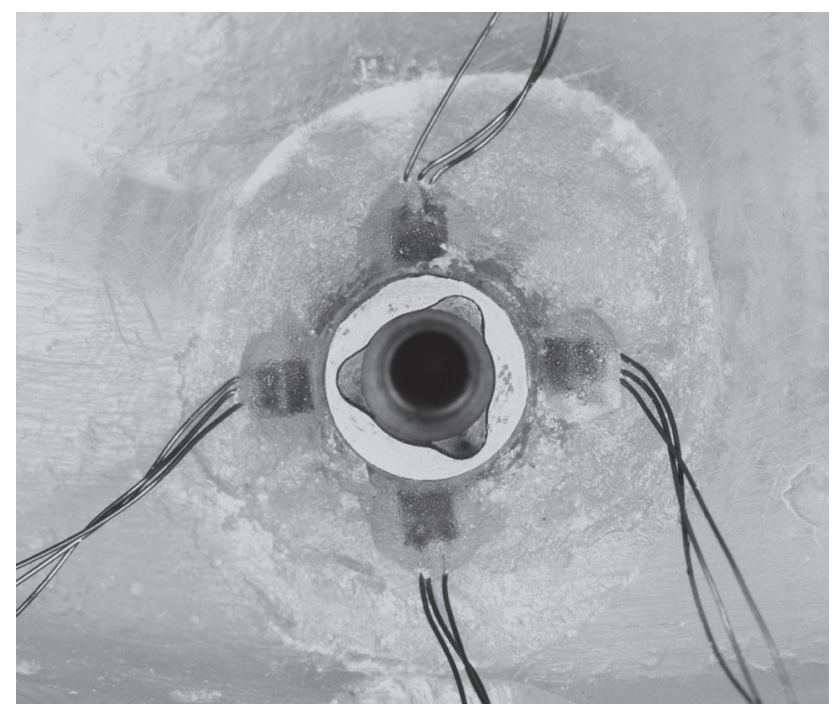

Fig. 3 Four strain gauges attached to the mesial, distal, buccal and lingual sides of the resin surface adjacent to the left implant.
Round Bar, Cendres+Métaux, Biel, Switzerland).

2. Ball attachment: The ball attachment consisted of a titanium ball abutment (Ball Abutment Titanium, Nobel Biocare), $2.25 \mathrm{~mm}$ in diameter, and a gold cap (Gold Cap Ball Abutment, Nobel Biocare).

3. Magnetic attachment: The magnetic attachment consisted of a flat-type magnetic assembly (Magfit DXC, Aichi Steel Corporation, Aichi, Japan), 4.7

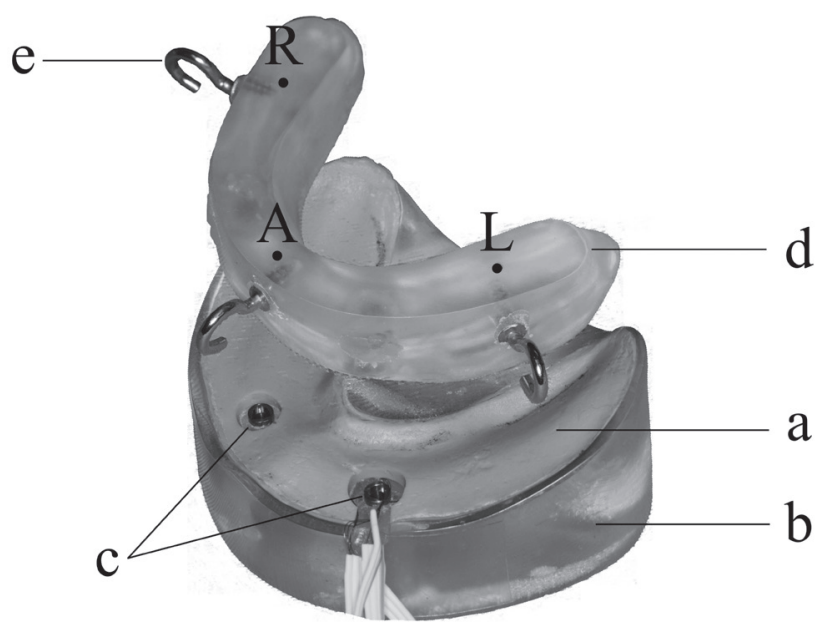

Fig. 2 Edentulous mandibular test model and experimental overdenture. (a) silicone artificial mucosa, (b) acrylic edentulous mandibular model, (c) two implants placed bilaterally in the canine regions, (d) acrylic experimental overdenture, (e) three hooks for attachment of chains in dislodging test.

$A$, $L$ and $R$ on the occlusal surface of the experimental overdenture indicate the loading points for loading test: (A) mid-anterior region, (L) left first molar region, (R) right first molar region.

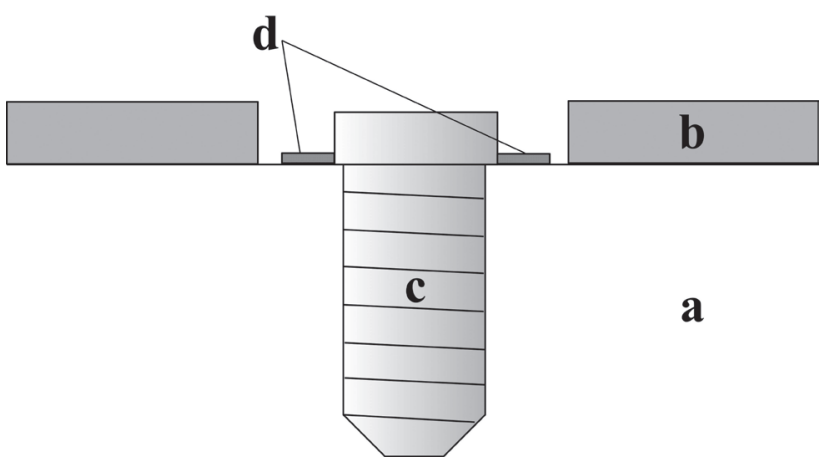

Fig. 4 Cross-sectional scheme of the left implant, the strain gauges and the test model. (a) acrylic edentulous mandibular model, (b) silicone artificial mucosa, (c) left implant, (d) strain gauges. 


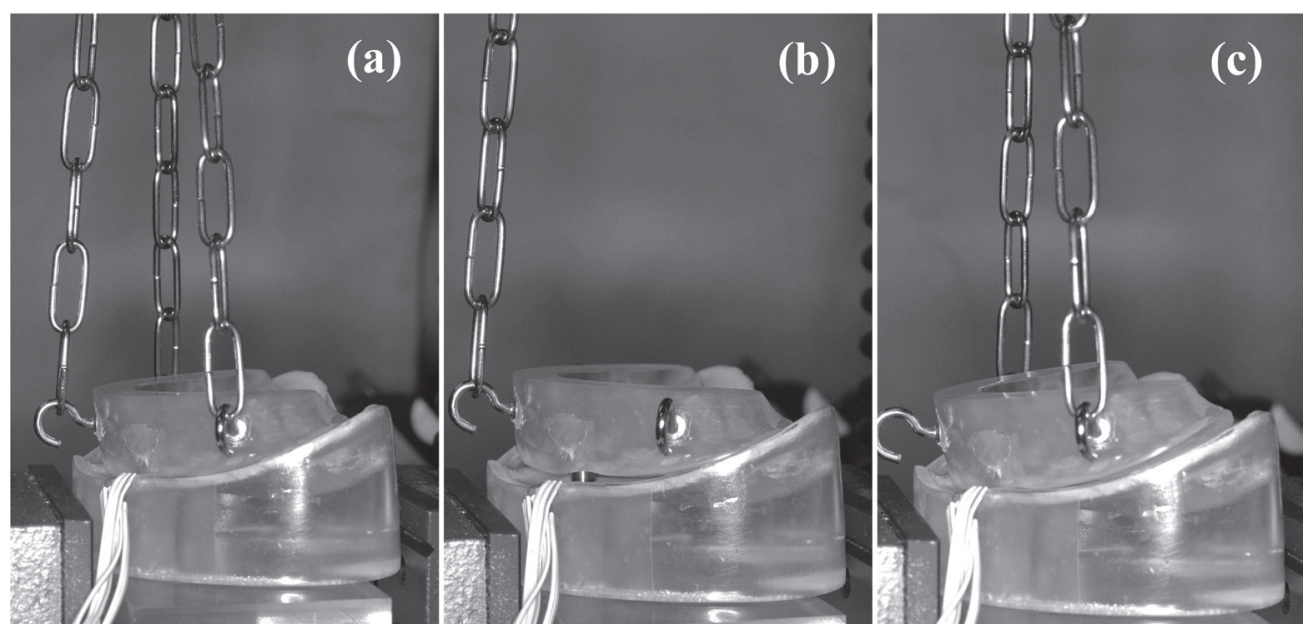

Fig. 5 Three types of dislodgement. (a) vertical dislodgement with three chains attached to the hooks in the mid-anterior and bilateral molar regions, (b) anterior dislodgement with one chain attached to the hook in the mid-anterior region, (c) posterior dislodgement with two chains attached to the hooks in the bilateral molar regions.

$\mathrm{mm}$ in diameter and $7.5 \mathrm{~N}$ in retentive force, and a keeper construction (Magfit IP-VFD30, Aichi Steel Corporation).

\section{Test model}

An edentulous mandibular test model simulating a severely resorbed ridge was fabricated from a heatpolymerizing acrylic resin (Acron clear, GC Corporation, Tokyo, Japan) (Fig. 2). No undercuts were left in this model. The surface of the denture bearing area was replaced by a 2 -mm-thick layer of a silicone impression material (Examixfine regular type, GC Corporation), which served as artificial mucosa. The elastic modulus of silicone materials was reported to be in the same range with that of the oral mucosa ${ }^{24)}$. Two implants (Replace Select Tapered, Nobel Biocare), $4.3 \mathrm{~mm}$ in diameter and $13 \mathrm{~mm}$ in length, were placed parallel to each other in the canine regions at a distance of $22 \mathrm{~mm}$, similar to the distance between two natural canines ${ }^{25}$, and fixed using an autopolymerising resin (Repairsin clear, GC Corporation).

Four uniaxial strain gauges (SKF23441, Kyowa Electronic Instruments Co., Ltd., Tokyo, Japan) were attached to the mesial, distal, buccal and lingual sides of the resin surface adjacent to the left implant (Figs. 3, 4) and connected to a sensor interface (PCD300A, Kyowa Electronic Instruments Co., Ltd.).

\section{Experimental overdentures}

Three identical experimental overdentures were fabricated from a multipurpose pourable resin (Procast DSP clear, GC Corporation) (Fig. 2). Three metal hooks were attached to the buccal surface of each experimental overdenture in the mid-anterior and bilateral molar regions for chains used in dislodging tests. The denture parts of the attachment systems were incorporated into the mucosal surfaces of the experimental overdentures using an autopolymerising resin (Unifast III, GC Corporation).

\section{Dislodging tests}

Overdenture dislodgements were performed using a universal testing machine (Instron model 5544, Instron Corporation, Norwood, MA, USA). The crosshead speed was $50 \mathrm{~mm} / \mathrm{min}$, as this has been reported to approximate the speed of the movement of the denture away from the ridge in $v i v o^{26}$. Three types of dislodgement were performed: vertical dislodgement with three chains attached to the hooks in the mid-anterior and bilateral molar regions; anterior dislodgement with one chain attached to the hook in the mid-anterior region; and posterior dislodgement with two chains attached to the hooks in the bilateral molar regions (Fig. 5). The maximum values from the sum of the absolute values of the recordings from the four strain gauges (strain), used as an indicator of the stress generated in the peri-implant bone, and maximum load needed to dislodge the experimental overdenture from the mandibular test model (retentive force) were calculated.

Five measurements each were performed in three types of dislodgement with three attachment systems, respectively. A total of 45 dislodgements were conducted for all three attachment systems.

\section{Loading tests}

Loading was performed using the universal testing machine. Loads with a magnitude of $100 \mathrm{~N}$, reported as a moderate level of biting force on implant overdentures ${ }^{27)}$, were applied to the experimental overdentures perpendicular to the occlusal plane. The loading points were left first molar region ipsilateral to the strain gauges (L), right first molar region contralateral to the strain gauges $(\mathrm{R})$ and mid-anterior region $(\mathrm{A})$ on the occlusal surface (Fig. 2). The maximum values from the 
sum of the absolute values of the recordings from the four strain gauges (strain) were calculated.

Five measurements were performed at each of the three different loading points with three attachment systems, respectively. A total of 45 loading tests were conducted for all three attachment systems.

\section{Statistical analysis}

The retentive forces and the strains obtained during dislodging tests and loading tests were compared using a one-way ANOVA and Tukey HSD test to identify statistically significant differences between the three attachment systems. In addition, retentive forces and strains during dislodging tests were compared using a one-way ANOVA and Tukey HSD test to identify statistically significant differences between the three types of dislodgement. All statistical analyses were performed using statistical analysis software (SPSS version 16.0, SPSS Inc., Chicago, IL, USA) and a $p$ value $<0.05$ was considered significant.

\section{RESULTS}

The retentive forces are shown in Table 1. The bar attachment showed the highest retentive force, while the magnetic attachment showed the lowest, during every type of dislodgement. A statistically significant difference was found between all attachment systems $(p=0.000)$. In

Table 1 Mean retentive force (N) in dislodging tests

\begin{tabular}{|c|c|c|c|c|}
\hline \multirow{2}{*}{ Type of dislodgement } & \multicolumn{3}{|c|}{ Attachment system } & \multirow{2}{*}{$\begin{array}{l}\text { Statistical significance } \\
\text { per attachment system }\end{array}$} \\
\hline & Bar & Ball & Magnet & \\
\hline Vertical & 100 (SD: 5.1) & $16.9(\mathrm{SD}: 2.7)$ & 4.9 (SD: 0.6) & $\begin{array}{l}\text { Bar }>\text { Ball }(p=0.000) \\
\text { Bar }>\text { Magnet }(p=0.000) \\
\text { Ball }>\text { Magnet }(p=0.000)\end{array}$ \\
\hline Anterior & 63.3 (SD: 0.6) & $15.1(\mathrm{SD}: 0.2)$ & 3.8 (SD: 1.1) & $\begin{array}{l}\text { Bar }>\text { Ball }(p=0.000) \\
\text { Bar }>\text { Magnet }(p=0.000) \\
\text { Ball }>\text { Magnet }(p=0.000)\end{array}$ \\
\hline Posterior & 46.1 (SD: 0.4) & 10.9 (SD: 1.8) & 1.8 (SD: 0.2) & $\begin{array}{l}\text { Bar }>\text { Ball }(p=0.000) \\
\text { Bar }>\text { Magnet }(p=0.000) \\
\text { Ball }>\text { Magnet }(p=0.000)\end{array}$ \\
\hline
\end{tabular}

$\begin{array}{llll}\text { Statistical significance } & \text { Ver }>\text { Ant }(p=0.000) & \text { Ver }>\operatorname{Pos}(p=0.001) & \text { Ver }>\operatorname{Pos}(p=0.000) \\ \text { per type of dislodgement } & \text { Ver }>\operatorname{Pos}(p=0.000) & \text { Ant }>\operatorname{Pos}(p=0.009) & \text { Ant }>\operatorname{Pos}(p=0.002)\end{array}$

Ant $>\operatorname{Pos}(p=0.000)$

Ver: Vertical dislodgement; Ant: Anterior dislodgement; Pos: Posterior dislodgement. Differences were considered significant at the $p<0.05$ level.

Table 2 Mean strain $(\mu \varepsilon)$ around the left implant in dislodging tests

\begin{tabular}{|c|c|c|c|c|}
\hline \multirow{2}{*}{ Type of dislodgement } & \multicolumn{3}{|c|}{ Attachment system } & \multirow{2}{*}{$\begin{array}{l}\text { Statistical significance } \\
\text { per attachment system }\end{array}$} \\
\hline & Bar & Ball & Magnet & \\
\hline Vertical & 189.8 (SD: 14.2) & 130 (SD: 21.2) & $28.4(\mathrm{SD}: 2.5)$ & $\begin{array}{l}\text { Bar }>\text { Ball }(p=0.000) \\
\text { Bar }>\text { Magnet }(p=0.000) \\
\text { Ball }>\text { Magnet }(p=0.000)\end{array}$ \\
\hline Anterior & 134.7 (SD: 37.9) & 102.1 (SD: 4.3) & 25.7 (SD: 3.6) & $\begin{array}{l}\text { Bar }>\text { Magnet }(p=0.000) \\
\text { Ball }>\text { Magnet }(p=0.000)\end{array}$ \\
\hline Posterior & 59.3 (SD: 1.6) & 109.7 (SD: 12.4) & $24.2(\mathrm{SD}: 3.5)$ & $\begin{array}{l}\text { Ball }>\text { Bar }(p=0.000) \\
\text { Ball }>\text { Magnet }(p=0.000) \\
\text { Bar }>\text { Magnet }(p=0.000)\end{array}$ \\
\hline $\begin{array}{l}\text { Statistical significance } \\
\text { per type of dislodgement }\end{array}$ & $\begin{array}{l}\text { Ver }>\text { Ant }(p=0.007) \\
\text { Ver }>\operatorname{Pos}(p=0.000) \\
\text { Ant }>\operatorname{Pos}(p=0.001)\end{array}$ & Ver $>$ Ant $(p=0.024)$ & NS & \\
\hline
\end{tabular}

Ver: Vertical dislodgement; Ant: Anterior dislodgement; Pos: Posterior dislodgement. Differences were considered significant at the $p<0.05$ level. 
Table 3 Mean strain $(\mu \varepsilon)$ around the left implant in loading tests

\begin{tabular}{|c|c|c|c|c|}
\hline \multirow{2}{*}{ Loading point } & \multicolumn{3}{|c|}{ Attachment system } & \multirow{2}{*}{$\begin{array}{l}\text { Statistical significance } \\
\text { per attachment system }\end{array}$} \\
\hline & Bar & Ball & Magnet & \\
\hline $\mathrm{L}$ & 241 (SD: 11.1) & 597 (SD: 25.9) & $97.6^{*}(\mathrm{SD}: 15.4)$ & $\begin{array}{l}\text { Ball }>\text { Bar }(p=0.000) \\
\text { Ball }>\text { Magnet }(p=0.000) \\
\text { Bar }>\text { Magnet }(p=0.000)\end{array}$ \\
\hline $\mathrm{R}$ & 152 (SD: 20.1) & 502 (SD: 40.7) & $41.2^{*}(\mathrm{SD}: 13.1)$ & $\begin{array}{l}\text { Ball }>\text { Bar }(p=0.000) \\
\text { Ball }>\text { Magnet }(p=0.000) \\
\text { Bar }>\text { Magnet }(p=0.000)\end{array}$ \\
\hline A & 98.8 (SD: 5.7 ) & 122 (SD: 4.0) & 152 (SD: 13.0) & $\begin{array}{l}\text { Magnet }>\text { Ball }(p=0.000) \\
\text { Magnet }>\operatorname{Bar}(p=0.000) \\
\text { Ball }>\operatorname{Bar}(p=0.004)\end{array}$ \\
\hline
\end{tabular}

L: Left first molar region ipsilateral to the strain gauges; R: Right first molar region contralateral to the strain gauges; A: Mid-anterior region.

Differences were considered significant at the $p<0.05$ level.

*Under occlusal force to the left or right first molar region $(\mathrm{L}, \mathrm{R})$, the overdenture retained by the magnetic attachment showed greater movement, thus detaching the magnetic assemblies from the keeper constructions, especially at the nonloading side.

addition, all attachment systems showed the highest retentive forces during vertical dislodgement, followed by anterior dislodgement and posterior dislodgement. A statistically significant difference was found between all types of dislodgement $(p<0.01)$, except between vertical dislodgement and anterior dislodgement with the ball attachment and magnetic attachment.

Strains in dislodging tests are shown in Table 2. During vertical dislodgement, the bar attachment caused the largest strain, followed by the ball attachment and the magnetic attachment, with a statistically significant difference between all attachment systems $(p=0.000)$. During anterior dislodgement, the magnetic attachment showed significantly smaller strain than the bar attachment and the ball attachment $(p=0.000)$. During posterior dislodgement, the ball attachment demonstrated the largest strain, followed by the bar attachment and the magnetic attachment, with a statistically significant difference between all attachment systems $(p=0.000)$. With the bar attachment, vertical dislodgement showed the largest strain, followed by anterior dislodgement and posterior dislodgement, with a statistically significant difference between all types of dislodgement $(p<0.01)$. With the ball attachment, vertical dislodgement showed larger strain than anterior dislodgement $(p=0.024)$. With the magnetic attachment, no statistical significant difference in strain was detected between the three types of dislodgement.

Strains in loading tests are shown in Table 3. When the left or right first molar regions (L, R) were loaded, the ball attachment showed the largest strain, followed by the bar attachment and the magnetic attachment, with a statistically significant difference between all attachment systems $(p=0.000)$. When the mid-anterior region (A) was loaded, the magnetic attachment showed the largest strain, followed by the ball attachment and the bar attachment, with a statistically significant difference between all attachment systems $(p<0.01)$.

\section{DISCUSSION}

The bar attachment was most retentive, while the magnetic attachment was least retentive, during every type of dislodgement. This is in agreement with other studies ${ }^{28-31}$. All attachment systems showed significantly lower retentive forces during anterior and posterior dislodgement compared to those during vertical dislodgement. Retentive forces of ball attachments with gold caps $^{32)}$ and magnetic attachments ${ }^{33)}$ in the oblique direction were reported to be lower than those in the vertical direction, which corresponds with the results of the present study.

Stress generated in the peri-implant bone during overdenture dislodgement has not been investigated in detail. During vertical dislodgement, the bar attachment showed the largest strain around the implant, followed by the ball attachment and the magnetic attachment. This order was the same as that of retentive forces during vertical dislodgement. Therefore, retentive forces of attachment systems probably affect stresses generated in the peri-implant bone during vertical dislodgement. With the bar attachment, the largest strain was measured during vertical dislodgement, followed by anterior dislodgement and posterior dislodgement. Although strain during vertical dislodgement with the bar attachment was the largest, dislodging the overdenture by holding the posterior region upwards reduced this strain. Therefore, implant overdentures retained by bar attachments should be removed with caution when osseointegration is not complete, as in immediate loading. The ball attachment showed relatively large strain during every type of dislodgement. The magnetic attachment exhibited the smallest strain during overdenture dislodgement among all types of 
attachment systems. For this reason, the magnetic attachment may be the most appropriate attachment system for the purpose of reducing the stress generated in the peri-implant bone during overdenture dislodgement.

Strains generated in the peri-implant bone when occlusal force was applied at the molar regions $(\mathrm{L}, \mathrm{R})$ were the largest with the ball attachment, followed by the bar attachment and the magnetic attachment. Bar attachments were reported to compensate for the resilience of the oral mucosa by free rotation of overdentures under occlusal forces, and this rotation reduces the stress transmitted to the implant ${ }^{34)}$. Cekiç et al. reported that bar attachments caused smaller strain to the peri-implant bone under occlusal force than ball attachments with gold caps because of rigid splinting of implants ${ }^{22)}$. With the magnetic attachment, occlusal forces to the molar regions $(\mathrm{L}, \mathrm{R})$ caused sinking of the overdenture in the loading-side molar region, thus detaching the magnetic assemblies from the keeper constructions, especially on the nonloading side. As a result, the magnetic attachment caused the smallest strain under loading at molar regions (L, R). On loading at the mid-anterior region (A), the magnetic attachment exhibited significantly larger strain than the other two attachment systems because the planar contacts between the flat type magnetic assemblies and keeper constructions were retained. Therefore, in terms of stress generated in the peri-implant bone under occlusal force, in immediate loading, bar attachments and magnetic attachments seem to be more advantageous than ball attachments with gold caps.

Forces to immediately loaded implants can easily disturb the osseointegration ${ }^{14)}$ and should be avoided. In terms of retentive force and stress, the bar attachment, showing the highest retentive force and comparably smaller strain under occlusal force, was suggested to be an effective attachment system, especially in immediate loading. Setz et al. suggested that a retentive force of 20 $\mathrm{N}$ would be sufficient for overdentures in the edentulous mandible ${ }^{35)}$, and only the bar attachment showed a retentive force greater than $20 \mathrm{~N}$ in the present study. Stress generated in the peri-implant bone during overdenture dislodgement with the bar attachment can be reduced by holding the posterior region upwards. Meanwhile, the actual selection criteria for attachment systems in immediate loading of implants supporting mandibular overdentures are more complex. Freestanding attachments can be incorporated into the overdenture intraorally immediately after implant placement, and free-standing attachments are more advantageous than bar attachments which require impression taking and laboratory work. The ball attachments with the gold caps exhibited large strain during dislodgement and loading, and restricted removal of the overdenture and prohibition of chewing hard food may be necessary in immediate loading of implants supporting overdentures retained by ball attachments with gold caps. The magnetic attachment showed the lowest retentive force and the smallest strain during dislodgement and loading. Therefore, immediate loading of implants supporting mandibular overdentures with magnetic attachments seems to be an undeniable treatment option, especially in cases requiring low degree of retentive force from attachment systems.

\section{REFERENCES}

1) Anderson GF, Hussey PS. Population aging: a comparison among industrialized countries. Health Aff (Millwood) 2000; 19: 191-203.

2) Petersen PE, Yamamoto T. Improving the oral health of older people: the approach of the WHO Global Oral Health Programme. Community Dent Oral Epidemiol 2005; 33: 81-92.

3) Douglass CW, Shih A, Ostry L. Will there be a need for complete dentures in the United States in 2020? J Prosthet Dent 2002; 87: 5-8.

4) Feine JS, Carlsson GE, Awad MA, Chehade A, Duncan WJ, Gizani S, Head T, Heydecke G, Lund JP, MacEntee M, Mericske-Stern R, Mojon P, Morais JA, Naert I, Payne AG, Penrod J, Stoker GT, Tawse-Smith A, Taylor TD, Thomason JM, Thomson WM, Wismeijer D. The McGill consensus statement on overdentures. Mandibular two-implant overdentures as first choice standard of care for edentulous patients. Gerodontology 2002; 19: 3-4.

5) Brånemark PI. Osseointegration and its experimental background. J Prosthet Dent 1983; 50: 399-410.

6) Rungcharassaeng K, Kan JY. Immediately loaded mandibular implant bar overdenture: a surgical and prosthodontic rationale. Int J Periodontics Restorative Dent 2000; 20: 71-79.

7) Cochran DL, Morton D, Weber HP. Consensus statements and recommended clinical procedures regarding loading protocols for endosseous dental implants. Int $\mathrm{J}$ Oral Maxillofac Implants 2004; 19 (Suppl): 109-113.

8) Stricker A, Gutwald R, Schmelzeisen R, Gellrich NG. Immediate loading of 2 interforaminal dental implants supporting an overdenture: clinical and radiographic results after 24 months. Int J Oral Maxillofac Implants 2004; 19: 868-872.

9) Marzola R, Scotti R, Fazi G, Schincaglia GP. Immediate loading of two implants supporting a ball attachmentretained mandibular overdenture: a prospective clinical study. Clin Implant Dent Relat Res 2007; 9: 136-143.

10) Kronstrom M, Davis B, Loney R, Gerrow J, Hollender L. A prospective randomized study on the immediate loading of mandibular overdentures supported by one or two implants: a 12-month follow-up report. Int J Oral Maxillofac Implants 2010; 25: 181-188.

11) Liao KY, Kan JY, Rungcharassaeng K, Lozada JL, Herford AS, Goodacre CJ. Immediate loading of two freestanding implants retaining a mandibular overdenture: 1-year pilot prospective study. Int J Oral Maxillofac Implants 2010; 25: 784-790.

12) Roe P, Kan JY, Rungcharassaeng K, Lozada JL, Kleinman AS, Goodacre CJ, Chen JW. Immediate loading of unsplinted implants in the anterior mandible for overdentures: a case series. Int J Oral Maxillofac Implants 2010; 25: 1028-1035.

13) Pae A, Kim JW, Kwon KR. Immediate loading of two implants supporting a magnet attachment-retained overdenture: one-year clinical study. Implant Dent 2010; 19: 428-436.

14) Isidor F. Influence of forces on peri-implant bone. Clin Oral Implants Res 2006; 17 Suppl 2: 8-18.

15) Mericske-Stern R, Piotti M, Sirtes G. 3-D in vivo force measurements on mandibular implants supporting overdentures. A comparative study. Clin Oral Implants Res 1996; 7: 387-396. 
16) Duyck J, Van Oosterwyck H, Vander Sloten J, De Cooman M, Puers R, Naert I. In vivo forces on oral implants supporting a mandibular overdenture: the influence of attachment system. Clin Oral Investig 1999; 3: 201-207.

17) Menicucci G, Lorenzetti M, Pera P, Preti G. Mandibular implant-retained overdenture: a clinical trial of two anchorage systems. Int J Oral Maxillofac Implants 1998; 13: 851-856.

18) Kenney R, Richards MW. Photoelastic stress patterns produced by implant-retained overdentures. J Prosthet Dent 1998; 80: 559-564.

19) Tokuhisa M, Matsushita $Y$, Koyano K. In vitro study of a mandibular implant overdenture retained with ball, magnet, or bar attachments: comparison of load transfer and denture stability. Int J Prosthodont 2003; 16: 128-134.

20) Porter JA Jr, Petropoulos VC, Brunski JB. Comparison of load distribution for implant overdenture attachments. Int $J$ Oral Maxillofac Implants 2002; 17: 651-662.

21) Menicucci G, Lorenzetti M, Pera P, Preti G. Mandibular implant-retained overdenture: finite element analysis of two anchorage systems. Int J Oral Maxillofac Implants 1998; 13: 369-376.

22) Cekiç C, Akça K, Cehreli MC. Effects of attachment design on strains around implants supporting overdentures. Quintessence Int 2007; 38: e291-297.

23) Meijer HJ, Starmans FJ, Steen WH, Bosman F. A threedimensional, finite-element analysis of bone around dental implants in an edentulous human mandible. Arch Oral Biol 1993; 38: 491-496.

24) Inoue K, Arikawa H, Fujii K, Shinohara N, Kawahata N. Viscoelastic properties of oral soft tissue. 1. A method of determining elastic modulus of oral soft tissue. Dent Mater J 1985; 4: 47-53.

25) Sinclair PM, Little RM. Maturation of untreated normal occlusions. Am J Orthod 1983; 83: 114-123.

26) Sarnat AE. The efficiency of cobalt samarium (Co5Sm) magnets as retention units for overdentures. J Dent 1983; 11:
324-333.

27) Mericske-Stern R, Hofmann J, Wedig A, Geering AH. In vivo measurements of maximal occlusal force and minimal pressure threshold on overdentures supported by implants or natural roots: a comparative study, Part 1 . Int $\mathrm{J}$ Oral Maxillofac Implants 1993; 8: 641-649.

28) Naert I, Gizani S, Vuylsteke M, Van Steenberghe D. A 5-year prospective randomized clinical trial on the influence of splinted and unsplinted oral implants retaining a mandibular overdenture: prosthetic aspects and patient satisfaction. J Oral Rehabil 1999; 26: 195-202.

29) Petropoulos VC, Smith W, Kousvelari E. Comparison of retention and release periods for implant overdenture attachments. Int J Oral Maxillofac Implants 1997; 12: 176-185.

30) van Kampen F, Cune M, van der Bilt A, Bosman F. Retention and postinsertion maintenance of bar-clip, ball and magnet attachments in mandibular implant overdenture treatment: an in vivo comparison after 3 months of function. Clin Oral Implants Res 2003; 14: 720-726.

31) Chung KH, Chung CY, Cagna DR, Cronin RJ Jr. Retention characteristics of attachment systems for implant overdentures. J Prosthodont 2004; 13: 221-226.

32) Gulizio MP, Agar JR, Kelly JR, Taylor TD. Effect of implant angulation upon retention of overdenture attachments. $\mathrm{J}$ Prosthodont 2005; 14: 3-11.

33) Rutkunas V, Mizutani H, Takahashi H. Influence of attachment wear on retention of mandibular overdenture. J Oral Rehabil 2007; 34: 41-51.

34) Trakas T, Michalakis K, Kang K, Hirayama H. Attachment systems for implant retained overdentures: a literature review. Implant Dent 2006; 15: 24-34.

35) Setz I, Lee SH, Engel E. Retention of prefabricated attachments for implant stabilized overdentures in the edentulous mandible: an in vitro study. J Prosthet Dent 1998; 80: $323-329$. 